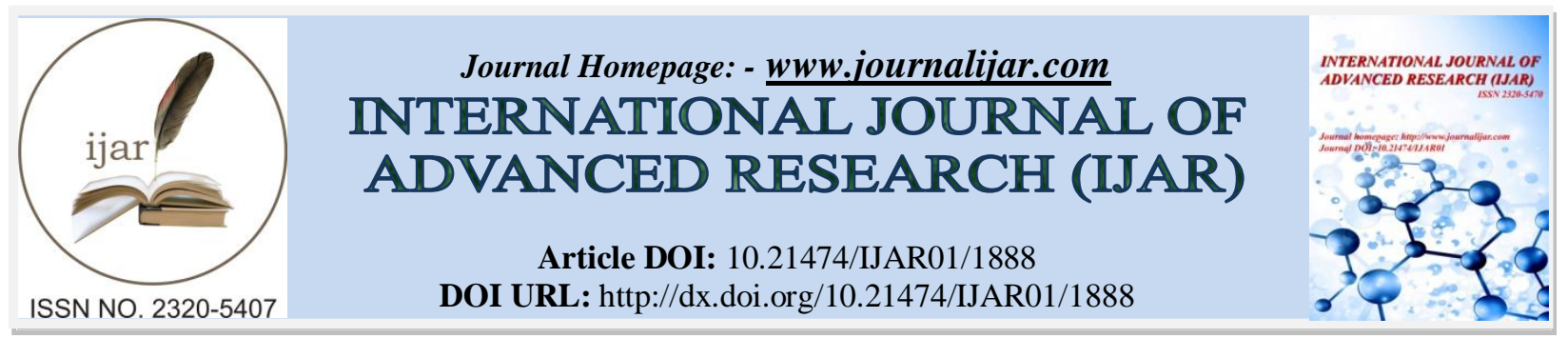

RESEARCH ARTICLE

\title{
DEVLOPEMNT OF MICROBIAL DIAGNOSTIC KIT FOR QUALITATIVE DETECTION OF MICROBIAL POPULATION IN BIOMANURES
}

\author{
Niteen Vinay Phirke ${ }^{1,2}$ \\ 1. P. G. Department of Microbiology, Sant Gadge Baba Amravati University, Amravati-444 602, India. \\ 2. Work done at Rural Development and Appropriate Technology, Indian Institute of Technology, Delhi.
}

\section{Manuscript Info}

Manuscript History

Received: 12 August 2016

Final Accepted: 22 September 2016

Published: October 2016

Key words:-

Composts, biomanures, diagnostics, kits, microbial quality of composts

\section{Abstract}

To fulfil the demand of quality biomanures and composts containing vibrant beneficial microbes, the qualitative check for the presence of effective microflora in biomanures is very much significant commercially. For checking the microbial contents of the compost products on site easily, qualitatively and cost-effectively, a portable microbial diagnostic kit for qualitative detection of microbial populations in biomanures has been scientifically conceptualized, designed, tested, developed and commercialized for the use by rural industrialists and entrepreneurs especially producing and selling composts and biomanures etc. The kit can give appropriately precise results within 24hours, by which an entrepreneur can decide about the microbial quality of the compost. The details regarding this invention are discussed herewith.

Copy Right, IJAR, 2016. All rights reserved.

\section{Introduction:-}

Composts are produced and used by farmers for maintaining soil fertility and agricultural productivity in sustainable manner. Due to world-wide upsurge of interest in organically grown food, composts have gained broad acceptability for its use and therefore, it is finding a financial value in the local, regional markets due to its inherent importance in enriching soil organic carbon and amending soil with a beneficial micro-biota. The economic value to these products of composting has resulted into its trade and there exists a perfect producer-consumer relationship. This necessitated it to have well-documented and studied technologies of production, sampling, quality control and assurance, storage etc. All the methods in relation to above topics are there except easy methods for determination of microbial properties.

The laboratory procedures for the detection of different microbial populations in the biomanure are lengthy, time, space and labour consuming. It also needs sophisticated instruments and costly media. Therefore, it is necessary to have certain means of detection of atleast quality of biomanure from microbial point of view (Phirke et al., 2004; Phirke, 2012). These efforts have been initiated for the development of microbial population testing kit.

The preliminary investigations in this regard, have revealed that microbes bear the capacity to reduce certain dyes through respiration. These dyes act as final hydrogen acceptor. There are several organic dyes available in market, which were tested. Among it, Bromocresol green, Malachite's green, safranine, methyl red, methylene blue were there for testing (Collins et al., 1980). The readymade formulations were available in alcohol. This alcohol hindered 
the microbial activity and therefore, aqueous dilute solutions were used. The aqueous solution of methylene blue was found effective.

\section{Materials and methods:- Composite compost sampling:-}

To get good results it is very essential to collect uniform samples. Compost heap should be mixed thoroughly and 56 samples from each heap, should be collected in such a way that the total heap gets proper chance to be sampled (Tandon, 1993; Phirke, 2002; Phirke, 2012). The samples should be properly packed in polythene bag and labelled. Each sample should be dried (shade dry) grounded and sieved before test. The samples should be stored in dry place to avoid absorption for moisture. If compost contains moisture it continues to decompose over a period of time due to microbial activity and degrades the quality of compost. Therefore, it is essential to test the samples immediately after collection and store it in a dry condition. Minimum 10-20 g of compost is required for the tests. For determination of microbial count, always fresh compost sample, having minimum 10-12\% moisture should be used.

\section{Media Preparation:-}

Nutrient broth [with composition Beef extract 3g, Peptone 5g, Methylene blue $(0.01 \% \mathrm{w} / \mathrm{v}) 100 \mathrm{ml}$, Distilled water $800 \mathrm{ml}, \mathrm{pH} 7.5$ adjusted using $0.1 \mathrm{~N} \mathrm{NaOH} / 0.1 \mathrm{~N} \mathrm{HCl}]$ amended with methylene blue was distributed in each vial in the quantity of $9 \mathrm{ml}$, sealed and autoclaved at $15 \mathrm{lb}$ pressure, $121^{\circ} \mathrm{C}$ for $15 \mathrm{~m}$ (Salle, 1954).

Potato dextrose medium [with composition: Boiled aqueous peeled off potato mash $1 \mathrm{Kg}$ was squeezed through clean cheese cloth to collect $200 \mathrm{~g}$ of extract, $100 \mathrm{~g}$ dextrose added, $\mathrm{pH}$ adjusted to 5.5 and volume was finalized to $800 \mathrm{ml}$. To it, $100 \mathrm{ml}$ methylene blue $(0.01 \% \mathrm{w} / \mathrm{v})$ solution was added] amended with methylene blue was distributed in each vial in the quantity of $9 \mathrm{ml}$, sealed and autoclaved at $15 \mathrm{lb}$ pressure, $121^{\circ} \mathrm{C}$ for $15 \mathrm{~m}$.

Jensen's medium [with composition Sucrose 20g, $\mathrm{K}_{2} \mathrm{HPO}_{4} 1 \mathrm{~g}, \mathrm{MgSO}_{4} 0.05 \mathrm{~g}, \mathrm{NaCl} 0.5 \mathrm{~g}, \mathrm{FeSO}_{4} 0.001 \mathrm{~g}, \mathrm{Na}_{2} \mathrm{MoO}_{4}$ $0.005 \mathrm{~g}, \mathrm{Ca}_{3}\left(\mathrm{CO}_{3}\right)_{2} 2 \mathrm{~g}$, Distilled water $800 \mathrm{ml}$, Methylene blue $(0.01 \% \mathrm{w} / \mathrm{v}) 100 \mathrm{ml}, \mathrm{pH} 7.5$ ] amended with methylene blue was distributed in each vial in the quantity of $9 \mathrm{ml}$, sealed and autoclaved at $15 \mathrm{lb}$ pressure, $121{ }^{\circ} \mathrm{C}$ for $15 \mathrm{~m}$ (Phirke, 2002).

Compost decoction has to be obtained by suspending approximately $1 \mathrm{~g}$ fresh compost composite sample in $10 \mathrm{ml}$ distilled water, vigorously shaking it to suspend all the microbes in water. And it was allowed to stand for a while to allow settling of coarse particles at the bottom, while microbes appeared in Brownian motion in the suspension. The control was also kept without inoculation of any microbial inoculum.

Graduated syringes of $2 \mathrm{ml}$ capacity are provided with the kit for sucking exactly $1 \mathrm{ml}$ of compost decoction with the help of needle. Using this needle, the sealed vial has to be pierced and exactly $1 \mathrm{ml}$ compost decoction has to be introduced into the vial. Along with this volume of compost decoction, all the microorganisms present are introduced in the medium, which provides nutrients for their growth. As per the selectivity of microbial medium, the respective microbial populations are selected, utilize the nutrients from the medium and get dominated to increase their number. This results into higher rate of metabolism, altering the colour through reduction of the dye.

Therefore, the sterilized vials (volume $30 \mathrm{ml}$ ) containing $9 \mathrm{ml}$ liquid nutrient medium, amended with aqueous solution of non-toxic, easily reducible organic dye in appropriate quantity to impart the colour to medium has to be inoculated with $1 \mathrm{ml}$ quantity of compost aqueous decoction.

The inoculated vials were kept for observation at room temperature. The colour was observed for twelve to twenty four hours and the time of discoloration of medium was noted every after half hour's interval. The microbes grow in the medium, respire and reduce the dye by changing its colour to original colour of the medium. This depends on the quantity of microbes present in the biomanure. More the microbes; earlier the colour will fade. Lower the microbes are present in compost; late the colour will fade. From the time required, it could be observed that what level of microbial group was present in the compost.

This process can be repeated to test 50 samples from one kit. Similar sterilized vials can be replaced to test more samples. 


\section{Results and Discussion:-}

The time required for fading of colour of the dye in the inoculated medium with the corresponding level of compostmicrobe-inoculum was optimized and the whole system was made in the ready-made form. Such sterile vials were designed and made available through the kit on the site where compost operators could just prepare the compost decoction and introduce it in the vial through syringe and wait for the colour change.

From the time required, it can be observed that the tested compost contains very high population, high level or moderate level or low-level population. From the time chart, it would be able to detect the levels of microbes present in a particular sample.

By using the selective media for the growth of desired organism, the presence and level of microbial population in the compost could be checked. Such as for the presence of bacterial population, fungal population, Azotobacter and Rhizobium population can be anticipated in given sample through kit to prove good for testing on site qualitatively. This microbial kit can also be added to the Biomanure diagnostic kit.

\section{Observations of the nutrient broth amended with methylene blue:}

The diluted compost decoction was inoculated at $10 \% \mathrm{v} / \mathrm{v}$ level in the nutrient broth tubes with methylene blue and incubated at room temperature for 24 hours. The $10^{-1}$ level showed speedily colour change within six hours, while rest took atleast 8 to 24 hours to get decolorize. This again depended upon the level of dilution. As the dilution level increased, overall time required for reduction of methylene blue also increased. But all the tubes were decolorized completely in 24 hours. The $\mathrm{pH}$ of the medium was kept 7.2 to selectively allow the growth of bacteria maximally. After 24 hours (Table 1.), one can observe the turbidity in the test tube. From these results, one can develop the qualitative broad ranges for determining the bacterial loads of the composts.

Table 1:- Observations of vials filled with the nutrient broth amended with methylene blue.

\begin{tabular}{|c|c|c|}
\hline Time (h) taken to get decolorized & Approximate bacterial population $\left(\mathrm{cfug}^{-1}\right)$ & Bacterial load of compost \\
\hline $6-8$ hours & $>10^{9}$ & Very high \\
\hline $8-12$ hours & $10^{7}-10^{9}$ & High \\
\hline $12-16$ hours & $10^{5}-10^{7}$ & Moderate \\
\hline $16-20$ hours & $10^{3}-10^{5}$ & Low \\
\hline $20-24$ hours & $10^{1}-10^{3}$ & Very low \\
\hline
\end{tabular}

Observations of the potato dextrose broth added with methylene blue:

The diluted compost decoction was inoculated at $10 \% \mathrm{v} / \mathrm{v}$ level in the PDB tubes with methylene blue and incubated at room temperature for 24 hours. The $10^{-1}$ level showed speedily colour change within six hours, while rest took atleast 8 to 24 hours to get decolorize. This again depended upon the level of dilution. As the dilution level increase, overall time required for reduction of methylene blue also increased. But all the tubes were decolorized completely in 24 hours. The $\mathrm{pH}$ of the medium was kept 5.5 to selectively allow the growth of fungi only. After 24 hours (Table 2.), one can observe the surface mycelial mat in the test tube. From these results, one can develop the qualitative broad ranges for determining the fungal load of the composts.

Table 2:- Observations of vials filled with potato dextrose broth added with methylene blue.

\begin{tabular}{|c|c|c|}
\hline Time (h) taken to get decolorized & Approximate fungal population $\left(\mathrm{cfug}^{-1}\right)$ & Fungal load of compost \\
\hline $6-8$ hours & $>10^{5}$ & Very high \\
\hline $8-12$ hours & $10^{4}-10^{5}$ & High \\
\hline $12-16$ hours & $10^{3}-10^{4}$ & Moderate \\
\hline $16-20$ hours & $10^{2}-10^{3}$ & Low \\
\hline $20-24$ hours & $10^{2}-10^{1}$ & Very low \\
\hline
\end{tabular}

Observations of the Jensen's broth amended with methylene blue:-

The diluted compost decoction was inoculated at $10 \% \mathrm{v} / \mathrm{v}$ level in the nutrient broth tubes with methylene blue and incubated at room temperature for 24 hours. The $10^{-1}$ level showed speedily colour change within six hours, while rest took atleast 8 to 24 hours to get decolorize. This again depended upon the level of dilution. As the dilution level increased, overall time required for reduction of methylene blue also increased. But all the tubes were decolorized 
completely in 24 hours. The $\mathrm{pH}$ of this nitrogen free medium was kept 7.2 to selectively allow the growth of Azotobacter only. After 24 hours (Table 3.), one can observe the turbidity in the test tube. From these results, one can develop the qualitative broad ranges for determining the bacterial loads of the composts.

Table 3:- Observations of vials filled with Jensen's broth amended with methylene blue.

\begin{tabular}{|c|c|c|}
\hline Time $(\mathrm{h})$ taken to get decolorized & Approximate Azotobacter population $\left(\mathrm{cfug}^{-1}\right)$ & Azotobacter load of compost \\
\hline $6-8$ hours & $>10^{7}$ & Very high \\
\hline $8-12$ hours & $10^{6}-10^{7}$ & High \\
\hline $12-16$ hours & $10^{5}-10^{6}$ & Moderate \\
\hline $16-20$ hours & $10^{4}-10^{5}$ & Low \\
\hline $20-24$ hours & $10^{3}-10^{4}$ & Very low \\
\hline
\end{tabular}

The determination of corresponding approximation in each microbial population with the time (h) taken to get decolourised and have turbidity in each vial have been established between the colony forming units per gm of compost samples ( $\mathrm{cfug}^{-1}$ ) using standard spread and pour plate technique inoculation in respective solid culture media (Collins et al., 1980; Phirke, 2002).

\section{Conclusions:-}

This kit (Photo 1.) would be a portable and easy for carrying anywhere in the field. This is anticipated to serve beneficial to rural entrepreneurs with a limited to nil facilities of compost testing. This kit would be a cost-effective and qualitatively precise. The kit is under trial and needs to be testified at sites by real end users and their suggestions in this feedback would be able to upgrade its applicability.

Photo 1:- Microbial diagnostic kit for qualitative detection of microbial populations in a biomanures.

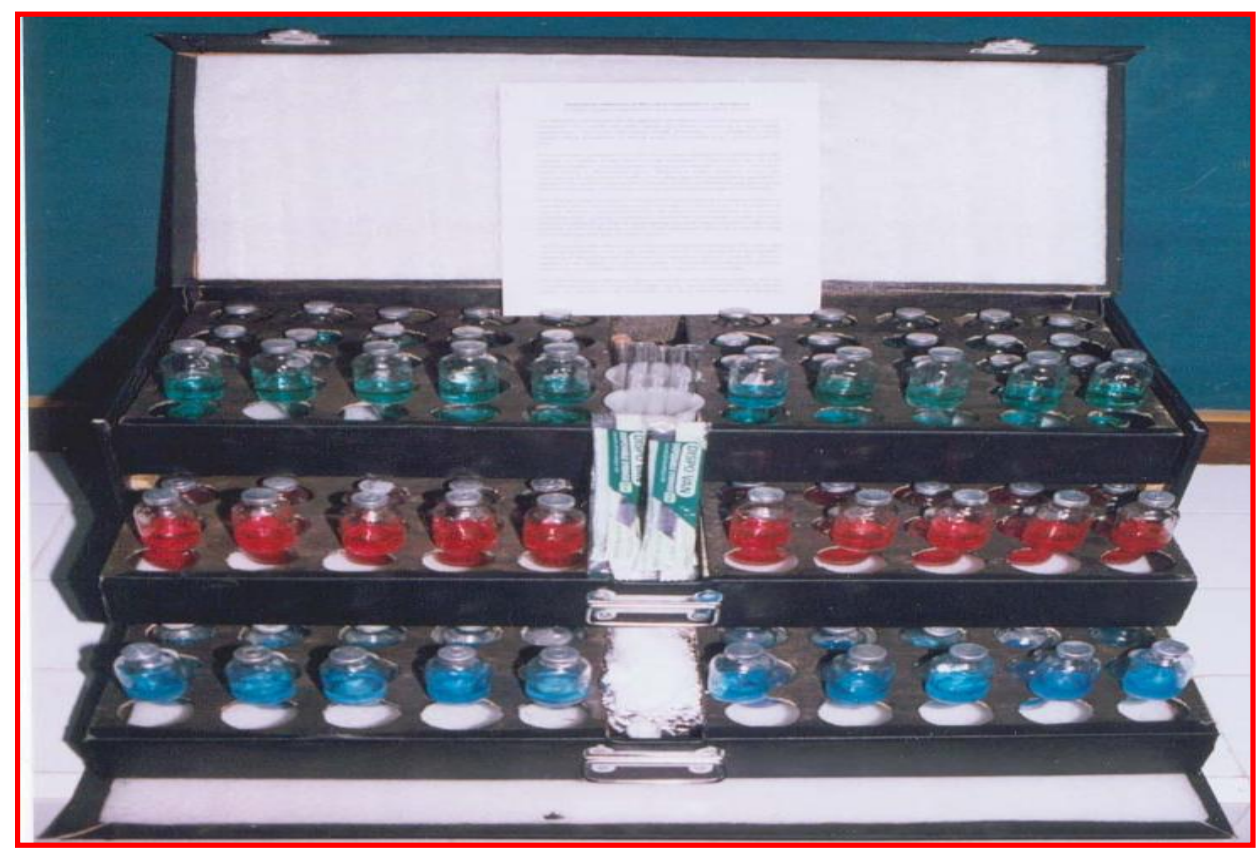

\section{Recommendations:-}

One drawback in using methylene blue in the system was found that the reduction of methylene blue was found reversible. If the tubes are shaken vigorously, the reduced and hyaline methylene blue turns blue again imparting its colour to the medium. Accidental shaking may hinder the observations, if such oxidation occurred. Hence, it is found necessary to search an alternative to this dye. The resazurin will be checked instead of methylene blue.

\section{Acknowledgements:-}

The author gratefully acknowledges the technical and financial help received from Indian Institute of Technology, Delhi under IRD project MI00185 to conduct several experiments in this regard and develop a handy, easy and portable Microbiological Diagnostic Kit for Biomanures. 


\section{References:-}

1. Collins, C. H. and Lyne, Patricia M. (1980) Microbiological Methods-Fourth Edition. Butterworth World Student Reprints.

2. Phirke, N. V. (2002) Biotech inputs for improving the yield of banana, Ph.D. Thesis, North Maharashtra University, Jalgaon.

3. Phirke, N. V. (2012) Inherited significance of organic matters and composts in sustainable soil fertility, pp. 7378, In: Proc. National conference on 'Recent trends in biosciences (RTIBS-2012)', G.S. College of Arts, Commerce and Science, Khamgaon, India.

4. Phirke, N. V., Joshi, P. and Chand, S. (2004) Microbiological Quality of Biomanures - Through a diagnostic kit. Jagriti, 48 (5): 54-55.

5. Salle, A. J. (1954) Laboratory Manual on Fundamental Principles of Bacteriology, McGraw-Hill Book Company Inc., pp.1-176.

6. Tandon, H.L.S. (Ed). (1993) Methods of analysis of soils, plants, waters and fertilizers FDCO, New Delhi, India. pp. 1-144. 